\title{
Clinicopathological features and prognostic significance of CTNNB1 mutation in low-grade, early-stage endometrial endometrioid carcinoma
}

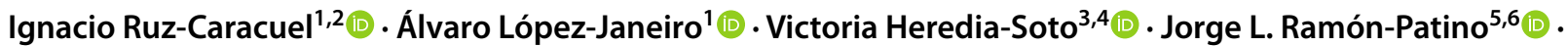 \\ Laura Yébenes $s^{1,7}$. Alberto Berjón ${ }^{1,7}$ - Alicia Hernández $z^{8,9}$ - Alejandro Gallego $0^{4,5}$ - Patricia Ruiz ${ }^{7}$.

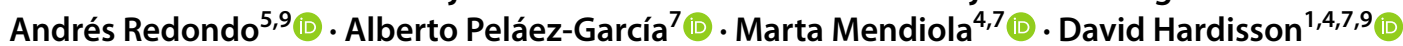

Received: 11 June 2021 / Revised: 14 July 2021 / Accepted: 2 August 2021 / Published online: 21 August 2021

(c) The Author(s) 2021

\begin{abstract}
Low-grade and early-stage endometrioid endometrial carcinomas (EECs) have an overall good prognosis but biomarkers identifying patients at risk of relapse are still lacking. Recently, $C T N N B 1$ exon 3 mutation has been identified as a potential risk factor of recurrence in these patients. We evaluate the prognostic value of CTNNB1 mutation in a single-centre cohort of 218 low-grade, early-stage EECs, and the correlation with beta-catenin and LEF1 immunohistochemistry as candidate surrogate markers. CTNNB1 exon 3 hotspot mutations were evaluated by Sanger sequencing. Immunohistochemical staining of mismatch repair proteins (MLH1, PMS2, MSH2, and MSH6), p53, beta-catenin, and LEF1 was performed in representative tissue microarrays. Tumours were also reviewed for mucinous and squamous differentiation, and MELF pattern. Nineteen (8.7\%) tumours harboured a mutation in CTNNB1 exon 3. Nuclear beta-catenin and LEF1 were significantly associated with $C T N N B 1$ mutation, showing nuclear beta-catenin a better specificity and positive predictive value for $C T N N B 1$ mutation. Tumours with $C T N N B 1$ exon 3 mutation were associated with reduced disease-free survival $(p=0.010)$, but no impact on overall survival was found $(p=0.807)$. The risk of relapse in tumours with $C T N N B 1$ exon 3 mutation was independent of FIGO stage, tumour grade, mismatch repair protein expression, or the presence of lymphovascular space invasion. CTNNBI exon 3 mutation has a negative impact on disease-free survival in low-grade, early-stage EECs. Nuclear beta-catenin shows a higher positive predictive value than LEF1 for CTNNB1 exon 3 mutation in these tumours.
\end{abstract}

Keywords Endometrial cancer · Endometrioid carcinoma - Low grade · Prognosis · CTNNB1 mutation · Beta-catenin · LEF1 $\cdot$ Microsatellite instability

\section{Introduction}

Endometrial cancer is the leading cause of gynaecological cancer and the third most frequent cancer in women [1]. Low-grade (histologic grade 1 or 2), early-stage (FIGO stage I-II) endometrioid endometrial carcinomas (EECs) have an overall good prognosis and are classified into low- or

Ignacio Ruz-Caracuel and Álvaro López-Janeiro contributed equally to this work.

\footnotetext{
Marta Mendiola

marta.mendiola@salud.madrid.org

$\triangle$ David Hardisson

david.hardisson@salud.madrid.org
}

Extended author information available on the last page of the article intermediate-risk categories using clinicopathological features [2-4]. However, between 4 and 13\% of these patients develop local or distance relapses [5, 6]. Early identification of these cases remains challenging.

Using data from endometrioid carcinomas of the TCGA project, Liu et al. identified $C T N N B 1$ exon 3 mutations as a potential risk factor of recurrence in low-grade, early-stage EECs [7]. This was later confirmed in most but not all studies [8-12]. Most of these reports are case-control studies $[8,11,12]$ and there is a lack of consecutive single-centre series with extensive morphological evaluation. Apart from the presence of squamous morules [13], little is known about other morphological features associated with the presence of this mutation.

Tumours carrying CTNNB1 exon 3 mutations activate the Wnt/beta-catenin through aberrant translocation of 
beta-catenin from the membrane to the nucleus, where it can be identified using immunohistochemistry (IHC) [14]. Betacatenin IHC has been repeatedly evaluated as a candidate surrogate marker of $C T N N B 1$ mutation with variable sensitivity and specificity [15]. Another candidate that has not yet been evaluated is LEF1, a nuclear effector of the Wnt/betacatenin pathway [16], overexpressed in CTNNB1-mutated tumours according to the Clinical Proteomic Tumour Analysis Consortium (CPTAC) proteogenomic characterisation of endometrial cancer [17].

The main objective of this study was to evaluate the prognostic impact of $C T N N B 1$ exon 3 hotspot mutation in a large series of low-grade, early-stage EECs. Additionally, we aimed to analyse the potential correlation of LEF1 and betacatenin IHC with CTNNB1 exon 3 hotspot mutation, and to identify morphological parameters that could be predictive of $C T N N B 1$ mutation in these tumours.

\section{Materials and methods}

\section{Cohort selection}

A single-centre retrospective cohort of EECs was identified from patients fulfilling the following criteria: primary EEC grade 1 or 2, FIGO 2009 stage I or II, hysterectomy and bilateral salpingo-oophorectomy performed between January 2003 and December 2015 at Hospital Universitario La Paz (Madrid, Spain), oncological follow-up at the same centre, and available tissue for exon $3 C T N N B 1$ mutation analysis. Clinicopathological features were retrieved from the pathological reports and the clinical records of the patients.

The study was approved by the local Ethics Committee (code HULP: PI-3108) and was conducted in accordance with ethical standards of the Helsinki Declaration of the World Medical Association.

\section{Histopathological analysis and immunohistochemistry}

All tumour slides were reviewed by one author (I.R.-C.) (mean \pm standard deviation: $6.84 \pm 3.23$, range: $1-24$ ) and discrepancies with original reports were solved with an experienced gynaecopathologist (D.H.). In addition, the following morphological variables were evaluated: mucinous differentiation; squamous differentiation; and the presence of microcystic, elongated, and fragmented (MELF) pattern of myoinvasion. Mucinous differentiation is defined as the presence of any percentage of cells with intracytoplasmastic mucin. Squamous differentiation is defined as any kind of squamous metaplasia, including morular metaplasia. MELF is defined as the presence of slit-like, microcystic, and/or individual tumour cells with eosinophilic change that are admixed with inflammation at the leading edge of the tumour [18]. Moreover, it was annotated if MELF pattern appeared as a predominant pattern or as a secondary pattern, as previously described [19].

Two representative central areas from each tumour were marked on haematoxylin-eosin slides and tissue microarrays (TMAs) containing cores of $1.2 \mathrm{~mm}$ were constructed using a TMA workstation (Beecher Instruments, Silver Spring, MD, USA), as described previously [19]. IHC was performed on 4- $\mu$ m sections of the TMA blocks by the Envision method (Dako-Agilent, Glostrup, Denmark) in an automated Omnis platform (Dako-Agilent) according to the manufacturer's instructions with the following monoclonal antibodies: beta-catenin ( $\beta$-catenin-1, Dako-Agilent; prediluted), LEF1 (EP310, Cell Marque, Sigma-Aldrich, Darmstadt, Germany; 1:100), and p53 (clone DO-7, Dako-Agilent; prediluted). DNA mismatch repair (MMR) proficiency was determined using the following primary antibodies: MLH1 (clone ES05, Dako-Agilent; prediluted), PMS2 (clone EP51, Dako-Agilent; prediluted), MSH2 (clone FE11, Dako-Agilent; prediluted), and MSH6 (clone EP49, Dako-Agilent; prediluted). Beta-catenin was evaluated as positive when any percentage of nuclear staining in tumour cells in any of the two cores was present and negative when no nuclear staining was observed. LEF1 evaluation on TMA was performed using the Allred score [20]. Briefly, the Allred score uses a visual scale to measure the percentage of nuclear staining from 0 to 5 and the intensity of nuclear staining from 0 to 3 . The final score is the sum of both variables. Final Allred score in tumours with two cores analysed was the mean of both values. An Allred score of $\geq 3$ was considered positive (LEF1 overexpression), to exclude cases with focal LEF1 expression sampled from the myoinvasive front. DNA MMR proteins (MLH1, PMS2, MSH2, and MSH6) were evaluated as positive (MMR-proficient) when any nuclear staining was present, irrespective of staining intensity, and negative (MMR-deficient) when no nuclear immunostaining was found. Cases were considered MMR-deficient when at least one MMR protein was negative. p53 immunostaining was interpreted according to current recommendations: tumours showing variable nuclear expression and intensity were noted as wild-type, tumours showing strong nuclei positivity in more than $80 \%$ of tumour cells or showing cytoplasmic staining in more than $80 \%$ of tumour cells were noted as aberrant-mutation pattern, and tumours showing complete absence of nuclei positivity were noted as nullmutation pattern [21]. In doubtful cases for MMR proteins and/or p53 evaluation, whole slide IHC was performed. Whole slide beta-catenin was also studied in tumours harbouring CTNNB1 mutation with absent beta-catenin staining on TMA. In addition to TMA, whole slide LEF1 expression was also evaluated in 21 non-selected cases of our series of EC. 


\section{Mutation testing of CTNNB1}

Selected formalin-fixed paraffin-embedded (FFPE) blocks containing $>50 \%$ of viable tumour tissue were used to extract DNA by QIAamp FFPE tissue kit (Qiagen) and used for PCR and Sanger sequencing. A $226 \mathrm{bp}$ fragment of $C T N N B 1$ exon 3 , encompassing the region of GSK-3 $\beta$ phosphorylation site, was amplified with these specific primers (5'-3'): GATTTGATGGAGTTGGACATGG and TGTTCT TGAGTGGAAGGACTGAG.

\section{Follow-up and statistical analysis}

Tumour relapse was defined as the occurrence of local tumour recurrence, lymph node metastasis, and/or distant metastasis. Disease-free survival (DFS) was defined as the time from the date of diagnosis to relapse or death due to any cause. Overall survival (OS) was defined as the time from the date of diagnosis to death due to any cause.

Quantitative results were expressed as mean \pm standard deviation. The chi-squared or Fisher's exact test was used to evaluate the association between qualitative variables. Mann-Whitney's $U$ test was used to evaluate the association between quantitative variables in both groups. Prognostic clinicopathological factors in CTNNB1 exon 3 mutated and non-mutated tumours in recurrence and non-recurrence groups were statistically analysed with univariate logistic regression. According to these results, multivariate logistic regression was modelled using the significant parameters $(p<0.05)$ from the univariate analysis and the age $\geq 60$ years. DFS and OS data were plotted in Kaplan-Meier curves, and the log-rank test was used to compare these parameters.

Data were analysed using the statistical software IBM SPSS v19 (Chicago, IL, USA). Differences were considered significant with $p$ values $<0.05$.

\section{Results}

\section{Cohort characteristics}

A total of 218 low-grade, early-stage EECs fulfilled the inclusion criteria. Table 1 shows the clinicopathological characteristics of the tumours grouped by CTNNB1 exon 3 mutational status. Nineteen $(8.7 \%)$ tumours harboured a mutation in CTNNB1 exon 3 (Supplementary table 1).

There were no significant differences between CTNNB1 exon 3 mutant and wild-type cases regarding established risk parameters, such as age, FIGO stage, tumour grade, and the presence of lymphovascular space invasion (LVSI) (Table 1). Moreover, there were no differences regarding adjuvant radiotherapy ( $p=0.484)$. No patient received adjuvant chemotherapy. Interestingly, $C T N N B 1$ exon 3 mutations were associated with higher risk of tumour relapse. Thus, there were 6 patients (31.6\%) who developed tumour relapse in the CTNNB1-mutated group compared with 21 patients (10.6\%) in the CTNNB1 wild-type group ( $p=0.018)$. Relapses in tumours with $C T N N B 1$ exon 3 mutation were locoregional in 4 patients and distant in 2 patients (metastases in mediastinal lymph nodes in one case, and multiple metastases in bone and liver in the other case).

CTNNB1 exon 3 mutations were significantly associated with certain morphological features, such as the presence of squamous differentiation $(p=0.003)$ and the absence of mucinous differentiation $(p=0.028)$. Only one tumour with $C T N N B 1$ exon 3 mutation showed a MELF pattern of myoinvasion.

A total of 216 (99\%) and 214 (98\%) cases were evaluable for DNA MMR protein expression and p53 by IHC, respectively. Failed cases were considered when any of the IHC for DNA MMR proteins showed no reactivity in the TMA and in the whole section. Eight tumours (3.9\%) showed a p53-mutant pattern (five cases showed diffuse overexpression of the p53 protein, and the remaining three tumours showed a null pattern confirmed by whole slide IHC). No case showed an abnormal cytoplasmic p53 pattern. In our series, all tumours with CTNNB1 exon 3 mutation were DNA MMR-proficient. We found that $C T N N B 1$ exon 3 mutation was mutually exclusive with alterations in p53 and DNA MMR.

\section{Prognostic significance of CTNNB1 exon 3 mutation in low-grade, early-stage EECs}

In our series, median follow-up was 80.50 months. The mean DFS was $80.37 \pm 44.05$ (range, $0-174$ ) months and mean OS was $84.04 \pm 41.68$ (range, 1-174) months. Patients with CTNNB1 exon 3 mutation had a mean DFS of $73.79 \pm 41.59$ (range, 10-144) months compared with $81.00 \pm 44.32$ (range, 0-174) months for patients with wild-type CTNNB1 exon 3 tumours $(p=0.010)$ (Fig. 1A). In contrast, OS was not significantly different for patients with or without CTNNB1 exon 3 mutation ( $83.37 \pm 43.00$ (range, 26-153) months vs $84.10 \pm 41.66$ (range, 1-174) months, respectively, $\mathrm{p}=0.807$ ) (Fig. 1B).

In the univariate logistic regression model, tumours harbouring a $C T N N B 1$ exon 3 mutation had a relative risk of relapse of $3.912(p=0.012)$ (Table 2). Classical clinicopathological parameters, such as tumour grade 2 vs grade 1 $(p=0.038)$, FIGO stage $\geq$ IB $(p<0.001)$, and the presence of LVSI $(p=0.001)$, were associated with tumour relapse in the univariate logistic regression model (Table 2).

A multivariate logistic regression model was calculated including the parameters reaching statistical significance $(p<0.05)$ in the univariate analysis; age $\geq 60$ years was 
Table 1 Clinicopathological characteristics of the patients

\begin{tabular}{|c|c|c|c|c|}
\hline & & $\begin{array}{l}C T N N B 1 \text { exon } 3 \\
\text { wild-type }\end{array}$ & $\begin{array}{l}C T N N B 1 \text { exon } 3 \\
\text { mutated }\end{array}$ & $p$-value \\
\hline Total number & 218 & $199(91.3 \%)$ & $19(8.7 \%)$ & \\
\hline Age (yr) & $64.04 \pm 10.38$ & $64.19 \pm 10.06$ & $62.47 \pm 13.54$ & 0.251 \\
\hline \multicolumn{5}{|l|}{ FIGO stage } \\
\hline IA & $149(68.3 \%)$ & $139(69.8 \%)$ & $10(52.6 \%)$ & \multirow[t]{3}{*}{0.304} \\
\hline IB & $61(28.0 \%)$ & $53(26.6 \%)$ & $8(42.1 \%)$ & \\
\hline II & $8(3.7 \%)$ & $7(3.5 \%)$ & $1(5.3 \%)$ & \\
\hline \multicolumn{5}{|c|}{ Adjuvant treatment } \\
\hline None & $153(70.2 \%)$ & $141(70.9 \%)$ & $12(63.2 \%)$ & \multirow[t]{2}{*}{0.484} \\
\hline Radiotherapy & $65(29.8 \%)$ & $58(29.1 \%)$ & $7(36.8 \%)$ & \\
\hline \multicolumn{5}{|l|}{ Tumour grade } \\
\hline G1 & $165(75.7 \%)$ & $149(74.9 \%)$ & $16(84.2 \%)$ & \multirow[t]{2}{*}{0.575} \\
\hline $\mathrm{G} 2$ & $53(24.3 \%)$ & $50(25.1 \%)$ & $3(15.8 \%)$ & \\
\hline \multicolumn{5}{|c|}{ Lymphovascular space invasion } \\
\hline Present & $38(17.4 \%)$ & $32(16.1 \%)$ & $6(31.6 \%)$ & \multirow[t]{2}{*}{0.110} \\
\hline Absent & $180(82.6 \%)$ & $167(83.9 \%)$ & $13(68.4 \%)$ & \\
\hline \multicolumn{5}{|c|}{ Tumour relapse } \\
\hline Yes & $27(12.4 \%)$ & $21(10.6 \%)$ & $6(31.6 \%)$ & \multirow[t]{2}{*}{0.018} \\
\hline No & $191(87.6 \%)$ & $178(89.4 \%)$ & $13(68.4 \%)$ & \\
\hline \multicolumn{5}{|c|}{ Squamous differentiation } \\
\hline Present & $81(37.2 \%)$ & $68(34.2 \%)$ & $13(68.4 \%)$ & \multirow[t]{2}{*}{0.003} \\
\hline Absent & $137(62.8 \%)$ & $131(65.8 \%)$ & $6(31.6 \%)$ & \\
\hline \multicolumn{5}{|c|}{ Mucinous differentiation } \\
\hline Present & $58(26.6 \%)$ & $57(28.6 \%)$ & $1(5.3 \%)$ & \multirow[t]{2}{*}{0.028} \\
\hline Absent & $160(73.4 \%)$ & $142(71.4 \%)$ & $18(94.7 \%)$ & \\
\hline \multicolumn{5}{|l|}{ MELF pattern } \\
\hline Present & $29(13.3 \%)$ & $28(14.1 \%)$ & $1(5.3 \%)$ & \multirow[t]{2}{*}{0.480} \\
\hline Absent & $189(86.7 \%)$ & $171(85.9 \%)$ & $18(94.7 \%)$ & \\
\hline \multicolumn{5}{|c|}{ DNA MMR protein expression } \\
\hline Proficient & $163(75.5 \%)$ & $144(73.1 \%)$ & $19(100 \%)$ & \multirow[t]{2}{*}{ Not calculated } \\
\hline Deficient & $53(24.5 \%)$ & $53(26.9 \%)$ & 0 & \\
\hline \multicolumn{5}{|c|}{ p53-mutant pattern } \\
\hline Present & $8(3.7 \%)$ & $8(4.1 \%)$ & 0 & \multirow[t]{2}{*}{ Not calculated } \\
\hline Absent & $206(96.3 \%)$ & $187(95.9 \%)$ & $19(100 \%)$ & \\
\hline \multicolumn{5}{|c|}{ Nuclear beta-catenin } \\
\hline Present & $24(11.3 \%)$ & $13(6.7 \%)$ & $11(57.9 \%)$ & \multirow[t]{2}{*}{$<0.001$} \\
\hline Absent & $188(88.7 \%)$ & $180(93.3 \%)$ & $8(42.1 \%)$ & \\
\hline \multicolumn{5}{|c|}{ LEF1 overexpression* } \\
\hline Present & $75(36.2 \%)$ & $62(32.8 \%)$ & $13(72.2 \%)$ & \multirow[t]{2}{*}{0.001} \\
\hline Absent & $132(63.8 \%)$ & $127(67.2 \%)$ & $5(27.8 \%)$ & \\
\hline
\end{tabular}

Bold values indicate statistically significant $p$ values $(p<0.05)$

*Allred score $\geq 3 ; M M R$, mismatch repair protein; $M E L F$, microcystic, elongated, and fragmented added to the multivariate model because it is a known parameter associated with relapse in endometrial cancer [2]. In the multivariate analysis, only CTNNBI exon 3 mutation and FIGO stage $\geq$ IB appeared to be independently and significantly associated with tumour recurrence ( $p=0.017$ and $p=0.020$, respectively) (Table 2). 
Fig. 1 Kaplan-Meier curves for disease-free survival (DFS) and overall survival (OS) in lowgrade, early-stage EECs. DFS (A) and OS (B) according to the presence of $C T N N B 1$ exon 3 mutation
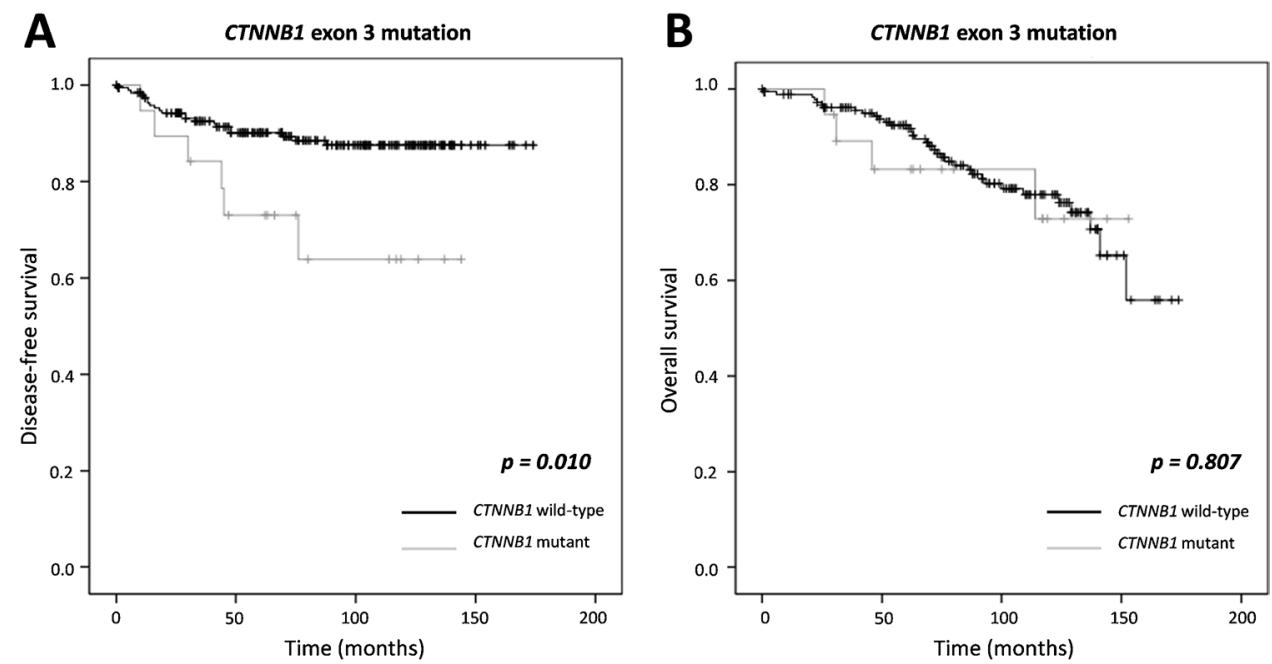

Table 2 Univariate and multivariate analyses of odds ratios in the logistic regression model with relapse as the dependent variable

\begin{tabular}{lrr}
\hline Parameter & Odds ratio (CI 95\%) & $p$-value \\
\hline Univariate logistic regression model & \\
Age $\geq 60$ years & $2.662(0.966-7.340)$ & 0.058 \\
Tumour grade 2 & $2.439(1.052-5.653)$ & $\mathbf{0 . 0 3 8}$ \\
FIGO stage $\geq$ IB & $3.347(1.744-6.421)$ & $<\mathbf{0 . 0 0 1}$ \\
LVSI & $4.176(1.751-9.957)$ & $\mathbf{0 . 0 0 1}$ \\
DNA MMR-deficient protein & $2.406(1.038-5.578)$ & $\mathbf{0 . 0 4 1}$ \\
expression & & \\
CTNNB1 exon 3 mutation & $3.912(1.345-11.380)$ & $\mathbf{0 . 0 1 2}$ \\
Multivariate logistic regression model & \\
Age $\geq 60$ years & $2.298(0.734-7.191)$ & 0.153 \\
Tumour grade 2 & $1.732(0.666-4.500)$ & 0.260 \\
FIGO stage $\geq$ IB & $3.129(1.197-8.178)$ & $\mathbf{0 . 0 2 0}$ \\
LVSI & $2.166(0.786-5.968)$ & 0.135 \\
DNA MMR-deficient protein & $2.361(0.868-6.421)$ & 0.092 \\
expression & & \\
CTNNB1 exon 3 mutation & $5.000(1.334-18.745)$ & $\mathbf{0 . 0 1 7}$ \\
\hline
\end{tabular}

Bold values indicate statistically significant $p$ values $(p<0.05)$

LVSI, lymphovascular space invasion; $M M R$, mismatch repair

\section{Pathological features associated with CTNNB1 mutation and correlation with beta-catenin and LEF1 immunohistochemistry}

LEF1 immunostaining was evaluable in 207 out of 218 cases; the remaining 11 cases were not evaluable due to technical issues. LEF1 nuclear expression was observed in $92(44.4 \%)$ out of 207 cases and an Allred score of $\geq 3$ was observed in $75(36.2 \%)$ tumours. Allred score was significantly higher in tumours with CTNNB1 mutation $(3.36 \pm 2.26)$ compared with $C T N N B 1$ wild-type tumours $(1.74 \pm 2.18)(p=0.004)$. Additionally, LEF1 IHC was performed in representative whole slides of 21 tumours. Two different patterns of LEF1 staining were identified. Firstly, eleven tumours showed LEF1 positive staining restricted to the invasive front (Fig. 2A). In contrast, ten tumours showed a diffuse or patchy overexpression of LEF1 in addition to that present at the invasive front (Fig. 2B).

In our TMA series, twenty-four (11.3\%) out of 212 evaluated tumours showed nuclear expression of beta-catenin. Six cases could not be evaluated due to technical issues. There was a positive significant association between the nuclear expression of beta-catenin and the overexpression of LEF1 (Allred score $\geq 3)(p=0.001)$. However, LEF1 and betacatenin were not always expressed in the same areas. Representative images of nuclear beta-catenin and LEF1 protein expression are shown in Fig. 2C-F.

To identify pathological parameters that can aid to identify $C T N N B 1$-mutated tumours, sensitivity and specificity of pathological features to predict CTNNB1 mutation were calculated in our series (Table 3). The most sensitive parameters were the absence of mucinous differentiation and the absence of MELF pattern. In contrast, the most specific parameter was nuclear beta-catenin IHC, followed by the presence of LVSI (Table 3).

Eleven (57.9\%) and 13 (72.2\%) cases with CTNNB1 exon 3 mutation showed nuclear expression of beta-catenin and overexpression of LEF1, respectively. Overexpression of LEF1 showed a higher sensitivity to predict $C T N N B 1$ exon 3 mutation compared to nuclear beta-catenin (Table 3). In contrast, nuclear beta-catenin showed a higher specificity (Table 3). The eight cases with CTNNB1 exon 3 mutation and absent nuclear beta-catenin expression in TMA were studied in representative whole slides, showing focal nuclear beta-catenin in four of them (50\%). 
Fig. 2 Immunohistochemical expression of LEF1 and beta-catenin. Representative areas from whole slide images of LEF1 staining showing a myoinvasive front restricted staining (A), in contrast to an overexpression pattern (B). Paired examples of a tumour showing a membranous betacatenin staining pattern without nuclear expression (C) and positive LEF1 nuclear staining (D) Paired examples of a tumour showing positive nuclear betacatenin $(\mathbf{E})$ and LEF1 expres$\operatorname{sion}(\mathbf{F})$

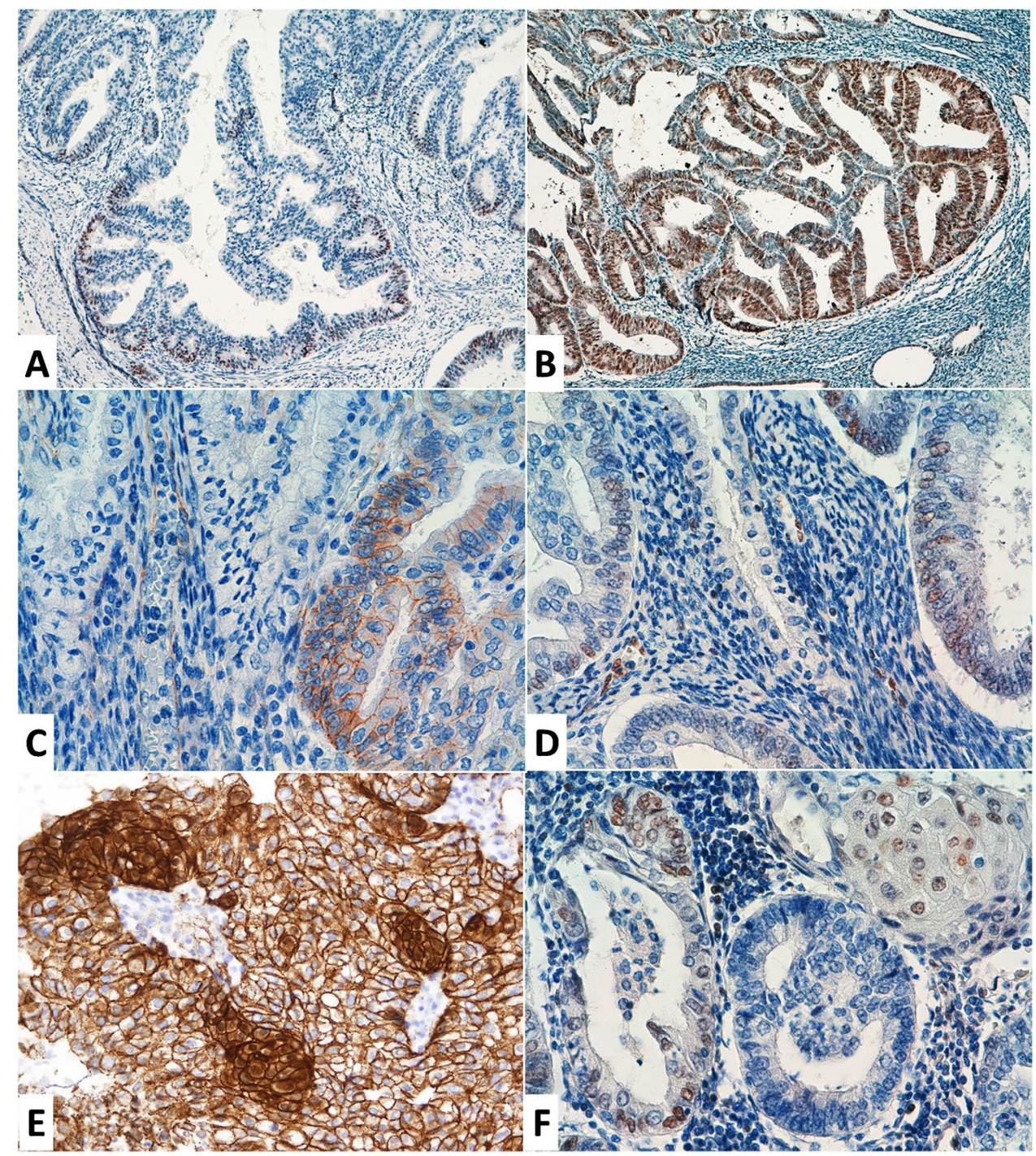

Table 3 Sensitivity and specificity of pathological parameters to predict $C T N N B 1$ exon 3 mutation

\begin{tabular}{llll}
\hline & $N$ & Sensitivity & Specificity \\
\hline Tumour grade 2 & 218 & 0.16 & 0.75 \\
LVSI & 218 & 0.32 & 0.84 \\
Squamous differentiation & 218 & 0.68 & 0.66 \\
Absence of mucinous differentiation & 218 & 0.95 & 0.29 \\
Absence of MELF pattern & 218 & 0.95 & 0.14 \\
Nuclear beta-catenin IHC & 212 & 0.58 & 0.93 \\
LEF 1 overexpression* & 207 & 0.67 & 0.72 \\
\hline
\end{tabular}

*Allred score $\geq 3$; LVSI, lymphovascular space invasion; $P P V$, positive predictive value; $N P V$, negative predictive value; $M E L F$, microcystic, elongated, and fragmented

DNA MMR protein expression and $\mathrm{p} 53$ pattern predictive values for $C T N N B 1$ mutation were not calculated, as there were no cases harbouring these alterations (Table 1).

\section{Discussion}

Our results demonstrate that $C T N N B 1$ exon 3 mutation is significantly associated with decreased DFS in patients with low-grade, early-stage EECs. This association is independent of other prognostic parameters currently used to risk stratification of patients such as age, tumour grade, FIGO stage, and LVSI in this population [3]. In contrast, no effect in OS was observed.

The association of CTNNB1 exon 3 mutation with recurrence in early-stage endometrial carcinomas was firstly described by Liu et al. [7]. These results were later confirmed by most authors [8-11], However, an important limitation of most of these studies is that they were designed as case-control studies [8, 10-12, 22], which may not be representative of the full spectrum of a complete series. In this sense, our study is one of the largest including a consecutive single-centre population of low-grade, early-stage EECs. 
Surprisingly, the percentage of CTNNB1-mutated tumours is lower $(8.7 \%)$ than that described in previous series [7-10]; however, we could not find any reason that could explain these discrepancies.

Interestingly, all tumours with $C T N N B 1$ exon 3 hotspot mutations in our series were DNA MMR-proficient. These results partly agree with those of Moroney et al. [23] showing a higher number of cases with $C T N N B 1$ exon 3 mutation in microsatellite stable tumours in a case-control descriptive study including grade 1, early-stage EECs. Moreover, in the TCGA study, $53 \%$ of tumours in the copy-number low and $19 \%$ in the microsatellite instability (hypermutated) categories harboured mutations in the CTNNB1 gene [24]. This suggests independent tumorigenic pathways, as already described in the literature [25]. CTNNB1 exon 3 mutation is mutually exclusive with mutant pattern p53 expression assessed by IHC, in accordance with data from the TCGA cohort that demonstrated few CTNNB1 mutations in the copy-number high subgroup, which is defined molecularly by TP53 mutation [24]. In this regard, a fifth molecular subgroup has been proposed comprising EECs with $C T N N B 1$ mutations that may have an intermediate prognosis [26]. Moreover, CTNNB1 mutations are considered in PORTEC4a, a clinical trial designed to assess histomolecular classification to assign different treatments in stage I and II EECs [27]. In addition, CTNNB1 mutation may be useful as a predictive biomarker. In this sense, it has been recently shown that spindle assembly checkpoint kinase TTK inhibitors, which are currently in phase I clinical trials, are more effective in $C T N N B 1$ mutant cell lines than in CTNNB1 wild-type lines [28].

Tumours with both nuclear beta-catenin and nuclear LEF1 protein expression were significantly associated with $C T N N B 1$ mutation. We assume that the low sensitivity of nuclear beta-catenin expression in detecting CTNNB1 mutation may be mainly due to the methodology used in the study. Thus, TMA may miss some areas of the tumour with focal nuclear expression of beta-catenin. In our series, half of the tumours harbouring CTNNB1 mutation and absent TMA beta-catenin expression showed focal nuclear expression in the whole slide. In this sense, Kim et al. recently reported that nearly half of endometrial carcinomas with nuclear expression of beta-catenin showed this pattern in only $5-10 \%$ of tumour cells [14].

LEF1 is a transcription factor, whose ability to transactivate is dependent on the arrangement and occupancy of the protein-binding sites surrounding the LEF1 binding site [29]. Beta-catenin is one of the main proteins that interacts with LEF1 causing its transactivation [29]. When LEF1 binds to beta-catenin, it activates epithelial-to-mesenchymal transition and cell proliferation [17]. Hence, LEF1 has been implicated in tumorigenesis and progression of several neoplasms [17], including endometrial cancer, where it has been suggested that it may have a potential value as a prognostic biomarker [30]. LEF1 IHC has been recently introduced as a useful tool in the diagnosis of solid-pseudopapillary neoplasm of the pancreas, a tumour with a gain-of-function mutation in CTNNB1 [31]. As expected, tumours harbouring $C T N N B 1$ exon 3 mutation showed a higher LEF1 Allred score in accordance with proteomic data from CPTAC study [17]. However, to the best of our knowledge, there are no studies that analyse the correlation between the expression of LEF1 and beta-catenin. According to our data, LEF1 correlates with $C T N N B 1$ exon 3 mutation with a slightly higher sensitivity than nuclear beta-catenin expression although the latter shows higher specificity. Considering these results, LEF1 IHC does not provide additional benefits to betacatenin IHC.

Another novel finding is our observation of the negative association between $C T N N B 1$ mutation and the presence of MELF pattern in these tumours. MELF pattern of myoinvasion was less common in CTNNB1 mutant than wild-type tumours (5.3\% vs $14.1 \%$ ), and this was a focal finding in the only case with CTNNB1 mutation. This suggests that MELF pattern of myoinvasion could reflect a molecular pathway independent of CTNNB1 mutation. In this regard, it is interesting that the MELF pattern of myoinvasion has been associated with the presence of single-cell metastases in locoregional lymph nodes without an impact on prognosis $[32,33]$. In contrast, tumours with $C T N N B 1$ exon 3 mutation are prone to develop tumour recurrence. An additional finding of our study is the negative association between CTNNB1 mutation and the presence of mucinous differentiation. Both features could be useful to select those ECs to test for CTNNB1 mutation based on pathological assessment.

Squamous differentiation (including morular alteration) showed a positive significant association with $C T N B B 1$ exon 3 hotspot mutations. This is to be expected because morular alteration, the most frequent squamous metaplasia in EECs, shows strong and diffuse nuclear beta-catenin expression associated with $C T N N B 1$ mutations in endometrial carcinomas $[13,34]$ and its precursors $[32,35]$.

One of the limitations of this study is the relatively low number of recurrences, a common problem in studies of lowgrade, early-stage EECs due to the low incidence of adverse events in these tumours. We must also take into account that for both MMR protein expression and p53 immunohistochemistry subclonal abnormal expression exists in a considerable number of cases; it is possible that this specific pattern may be missed when using a TMA approach, as we did in our study. Moreover, beta-catenin immunohistochemistry is known to show extensive intratumoral heterogeneity, and this may limit the interpretation of this protein in TMA.

In summary, we found that $C T N N B 1$ exon 3 mutation is associated with decreased DFS in low-grade, earlystage EECs. Moreover, the risk of relapse in tumours with 
CTNNB1 exon 3 mutation is independent of other clinicopathological prognostic factors, such as FIGO stage, tumour grade, DNA MMR-deficient protein expression, or presence of LVSI. This fact reinforces that CTNNB1-mutated tumours may be considered a fifth group of intermediate prognoses among low-grade, early-stage EECs, apart from already established TCGA molecular groups [24]. Morphological parameters such as the absence of mucinous differentiation and the absence of MELF pattern showed high sensitivity to identify CTNNB1-mutated tumours. IHC showing nuclear beta-catenin and LEF1 overexpression are associated with $C T N N B 1$ exon 3 mutation in these tumours, having nuclear beta-catenin a better specificity for $C T N N B 1$ mutation.

Supplementary Information The online version contains supplementary material available at https://doi.org/10.1007/s00428-021-03176-5.

Acknowledgements We wish to thank María Miguel and Roberto Crespo for excellent technical assistance. This research was conducted using the IdiPAZ Biobank Resource, which we thank for its excellent technical support.

Author contribution Conceptualisation: Ignacio Ruz-Caracuel, Alberto Peláez-García, Marta Mendiola, David Hardisson; methodology: Ignacio Ruz-Caracuel, Álvaro López-Janeiro, Victoria Heredia-Soto, Jorge L Ramón-Patino, Laura Yébenes, Alberto Berjón, Alicia Hernández, Alejandro Gallego, Patricia Ruiz, Andrés Redondo, Alberto PeláezGarcía, Marta Mendiola, David Hardisson; formal analysis and investigation: Ignacio Ruz-Caracuel, Álvaro López-Janeiro, Alberto PeláezGarcía, Marta Mendiola, David Hardisson; writing_original draft preparation: Ignacio Ruz-Caracuel, Álvaro López-Janeiro; writingreview and editing: Andrés Redondo, Alberto Peláez-García, Marta Mendiola, David Hardisson; funding acquisition: David Hardisson; resources and supervision: Alberto Peláez-García, Marta Mendiola, David Hardisson.

Funding Open Access funding provided thanks to the CRUE-CSIC agreement with Springer Nature. This research was funded by the Instituto de Salud Carlos III (ISCIII) (PI17/01723), co-financed by the European Development Regional Fund 'A way to achieve Europe' (FEDER).

Data availability Data is available upon author request.

Code availability Not applicable.

\section{Declarations}

Ethics approval The study was approved by the local Ethics Committee (code HULP: PI-3108).

Consent to participate Not applicable.

Consent for publication Not applicable.

Conflict of interest The authors declare no competing interests.

Open Access This article is licensed under a Creative Commons Attribution 4.0 International License, which permits use, sharing, adaptation, distribution and reproduction in any medium or format, as long as you give appropriate credit to the original author(s) and the source, provide a link to the Creative Commons licence, and indicate if changes were made. The images or other third party material in this article are included in the article's Creative Commons licence, unless indicated otherwise in a credit line to the material. If material is not included in the article's Creative Commons licence and your intended use is not permitted by statutory regulation or exceeds the permitted use, you will need to obtain permission directly from the copyright holder. To view a copy of this licence, visit http://creativecommons.org/licenses/by/4.0/.

\section{References}

1. Siegel RL, Miller KD, Fuchs HE, Jemal A (2021) Cancer statistics, 2021. CA Cancer J Clin 71:7-33. https://doi.org/10.3322/ caac. 21654

2. Bendifallah S, Canlorbe G, Collinet P, Arsene E, Huguet F, Coutant C, Hudry D, Graesslin O, Raimond E, Touboul C, Darai E, Ballester M (2015) Just how accurate are the major risk stratification systems for early-stage endometrial cancer? Br J Cancer 112:793-801. https://doi.org/10.1038/bjc.2015.35

3. Concin N, Creutzberg CL, Vergote I, Cibula D, Mirza MR, Marnitz S, Ledermann JA, Bosse T, Chargari C, Fagotti A, Fotopoulou C, Gonzalez-Martin A, Lax SF, Lorusso D, Marth C, Morice P, Nout RA, O'Donnell DE, Querleu D, Raspollini MR, Sehouli J, Sturdza AE, Taylor A, Westermann AM, Wimberger P, Colombo N, Planchamp F, Matias-Guiu X (2021) ESGO/ ESTRO/ESP Guidelines for the management of patients with endometrial carcinoma. Virchows Arch 478:153-190. https:// doi.org/10.1007/s00428-020-03007-z

4. Lu KH, Broaddus RR (2020) Endometrial cancer. N Engl J Med 383:2053-2064. https://doi.org/10.1056/NEJMra1514010

5. Jeppesen MM, Jensen PT, Gilsa Hansen D, Iachina M, Mogensen O (2016) The nature of early-stage endometrial cancer recurrence. A national cohort study. Eur J Cancer 69:51-60. https://doi.org/10.1016/j.ejca.2016.09.033

6. Francis SR, Ager BJ, Do OA, Huang YJ, Soisson AP, Dodson MK, Werner TL, Sause WT, Grant JD, Gaffney DK (2019) Recurrent early stage endometrial cancer: patterns of recurrence and results of salvage therapy. Gynecol Oncol 154:38-44. https://doi.org/10.1016/j.ygyno.2019.04.676

7. Liu Y, Patel L, Mills GB, Lu KH, Sood AK, Ding L, Kucherlapati R, Mardis ER, Levine DA, Shmulevich I, Broaddus RR, Zhang W (2014) Clinical significance of CTNNB1 mutation and Wnt pathway activation in endometrioid endometrial carcinoma. J Natl Cancer Inst 106:dju245. https://doi.org/10.1093/ jnci/dju245

8. Myers A, Barry WT, Hirsch MS, Matulonis U, Lee L (2014) BetaCatenin mutations in recurrent FIGO IA grade I endometrioid endometrial cancers. Gynecol Oncol 134:426-427. https://doi.org/ 10.1016/j.ygyno.2014.06.010

9. Stelloo E, Nout RA, Osse EM, Jurgenliemk-Schulz IJ, Jobsen JJ, Lutgens LC, van der Steen-Banasik EM, Nijman HW, Putter H, Bosse T, Creutzberg CL, Smit VT (2016) Improved risk assessment by integrating molecular and clinicopathological factors in early-stage endometrial cancer-combined analysis of the PORTEC cohorts. Clin Cancer Res 22:4215-4224. https://doi.org/10.1158/ 1078-0432.CCR-15-2878

10. Kurnit KC, Kim GN, Fellman BM, Urbauer DL, Mills GB, Zhang W, Broaddus RR (2017) CTNNB1 (beta-catenin) mutation identifies low grade, early stage endometrial cancer patients at increased risk of recurrence. Mod Pathol 30:1032-1041. https://doi.org/10. 1038/modpathol.2017.15 
11. Costigan DC, Dong F, Nucci MR, Howitt BE (2020) Clinicopathologic and immunohistochemical correlates of CTNNB1 mutated endometrial endometrioid carcinoma. Int J Gynecol Pathol 39:119-127. https://doi.org/10.1097/PGP.0000000000 000583

12. Stasenko M, Feit N, Lee SSK, Shepherd C, Soslow RA, Cadoo KA, Alektiar K, Da Silva EM, Martins Sebastiao AP, Leitao MM Jr, Gardner G, Selenica P, Abu-Rustum NR, Weigelt B, Mueller JJ (2020) Clinical patterns and genomic profiling of recurrent 'ultralow risk' endometrial cancer. Int J Gynecol Pathol 30:717-723. https://doi.org/10.1136/ijgc-2020-001241

13. Saegusa M, Okayasu I (2001) Frequent nuclear beta-catenin accumulation and associated mutations in endometrioid-type endometrial and ovarian carcinomas with squamous differentiation. $\mathbf{J}$ Pathol 194:59-67. https://doi.org/10.1002/path.856

14. Kim G, Kurnit KC, Djordjevic B, Singh C, Munsell MF, Wang WL, Lazar AJ, Zhang W, Broaddus R (2018) Nuclear beta-catenin localization and mutation of the CTNNB1 gene: a contextdependent association. Mod Pathol 31:1553-1559. https://doi. org/10.1038/s41379-018-0080-0

15. Travaglino A, Raffone A, Saccone G, De Luca C, Mollo A, Mascolo M, De Placido G, Insabato L, Zullo F (2019) Immunohistochemical nuclear expression of beta-catenin as a surrogate of CTNNB1 exon 3 mutation in endometrial cancer. Am J Clin Pathol 151:529-538. https://doi.org/10.1093/ajcp/aqy178

16. Santiago L, Daniels G, Wang D, Deng FM, Lee P (2017) Wnt signaling pathway protein LEF1 in cancer, as a biomarker for prognosis and a target for treatment. Am J Cancer 7:1389-1406

17. Dou Y, Kawaler EA, Cui Zhou D, Gritsenko MA, Huang C, Blumenberg L, Karpova A, Petyuk VA, Savage SR, Satpathy S, Liu W, Wu Y, Tsai CF, Wen B, Li Z, Cao S, Moon J, Shi Z, Cornwell M, Wyczalkowski MA, Chu RK, Vasaikar S, Zhou H, Gao Q, Moore RJ, Li K, Sethuraman S, Monroe ME, Zhao R, Heiman D, Krug K, Clauser K, Kothadia R, Maruvka Y, Pico AR, Oliphant AE, Hoskins EL, Pugh SL, Beecroft SJI, Adams DW, Jarman JC, Kong A, Chang HY, Reva B, Liao Y, Rykunov D, Colaprico A, Chen XS, Czekanski A, Jedryka M, Matkowski R, Wiznerowicz M, Hiltke T, Boja E, Kinsinger CR, Mesri M, Robles AI, Rodriguez H, Mutch D, Fuh K, Ellis MJ, DeLair D, Thiagarajan M, Mani DR, Getz G, Noble M, Nesvizhskii AI, Wang P, Anderson ML, Levine DA, Smith RD, Payne SH, Ruggles KV, Rodland KD, Ding L, Zhang B, Liu T, Fenyo D, Analysis CPT, C, (2020) Proteogenomic characterization of endometrial carcinoma. Cell 180(729-748):e726. https://doi.org/10.1016/j.cell.2020.01.026

18. Cole AJ, Quick CM (2013) Patterns of myoinvasion in endometrial adenocarcinoma: recognition and implications. Adv Anat Pathol 20:141-147. https://doi.org/10.1097/PAP.0b013e3182 $8 \mathrm{~d} 17 \mathrm{cc}$

19. Ruz-Caracuel I, Ramon-Patino JL, Lopez-Janeiro A, Yebenes L, Berjon A, Hernandez A, Gallego A, Heredia-Soto V, Mendiola M, Redondo A, Pelaez-Garcia A, Hardisson D (2019) Myoinvasive pattern as a prognostic marker in low-grade, early-stage endometrioid endometrial carcinoma. Cancers 11:1845. https://doi.org/ $10.3390 /$ cancers 11121845

20. Allred DC, Harvey JM, Berardo M, Clark GM (1998) Prognostic and predictive factors in breast cancer by immunohistochemical analysis. Mod Pathol 11:155-168

21. Singh N, Piskorz AM, Bosse T, Jimenez-Linan M, Rous B, Brenton JD, Gilks CB, Kobel M (2020) p53 immunohistochemistry is an accurate surrogate for TP53 mutational analysis in endometrial carcinoma biopsies. J Pathol 250:336-345. https://doi.org/ 10.1002/path.5375

22. Imboden S, Tapia C, Scheiwiller N, Kocbek V, Altermatt HJ, Janzen J, Mueller MD, McKinnon B (2020) Early-stage endometrial cancer, CTNNB1 mutations, and the relation between lymphovascular space invasion and recurrence. Acta Obstet Gynecol Scand 99:196-203. https://doi.org/10.1111/aogs.13740

23. Moroney MR, Davies KD, Wilberger AC, Sheeder J, Post MD, Berning AA, Fisher C, Lefkowits C, Guntupalli SR, Behbakht K, Corr BR (2019) Molecular markers in recurrent stage I, grade 1 endometrioid endometrial cancers. Gynecol Oncol 153:517-520. https://doi.org/10.1016/j.ygyno.2019.03.100

24. Cancer Genome Atlas Research N, Kandoth C, Schultz N, Cherniack AD, Akbani R, Liu Y, Shen H, Robertson AG, Pashtan I, Shen R, Benz CC, Yau C, Laird PW, Ding L, Zhang W, Mills GB, Kucherlapati R, Mardis ER, Levine DA (2013) Integrated genomic characterization of endometrial carcinoma. Nature 497:67-73. https://doi.org/10.1038/nature12113

25. Palacios J, Catasus L, Moreno-Bueno G, Matias-Guiu X, Prat J, Gamallo C (2001) Beta- and gamma-catenin expression in endometrial carcinoma. Relationship with clinicopathological features and microsatellite instability. Virchows Arch 438:464-469. https://doi.org/10.1007/s004280000371

26. Vermij L, Smit V, Nout R, Bosse T (2020) Incorporation of molecular characteristics into endometrial cancer management. Histopathology 76:52-63. https://doi.org/10.1111/his.14015

27. Wortman BG, Bosse T, Nout RA, Lutgens L, van der SteenBanasik EM, Westerveld H, van den Berg H, Slot A, De Winter KAJ, Verhoeven-Adema KW, Smit V, Creutzberg CL, Group PS (2018) Molecular-integrated risk profile to determine adjuvant radiotherapy in endometrial cancer: evaluation of the pilot phase of the PORTEC-4a trial. Gynecol Oncol 151:69-75. https://doi. org/10.1016/j.ygyno.2018.07.020

28. Zaman GJR, de Roos J, Libouban MAA, Prinsen MBW, de Man J, Buijsman RC, Uitdehaag JCM (2017) TTK inhibitors as a targeted therapy for CTNNB1 (beta-catenin) mutant cancers. Mol Cancer Ther 16:2609-2617. https://doi.org/10.1158/1535-7163. MCT-17-0342

29. Eastman Q, Grosschedl R (1999) Regulation of LEF-1/TCF transcription factors by Wnt and other signals. Curr Opin Cell Biol 11:233-240. https://doi.org/10.1016/s0955-0674(99)80031-3

30. Wu X, Han Y, Liu F, Ruan L (2020) Downregulations of miR449a and miR-145-5p act as prognostic biomarkers for endometrial cancer. J Comput Biol 27:834-844. https://doi.org/10.1089/ cmb.2019.0215

31. Singhi AD, Lilo M, Hruban RH, Cressman KL, Fuhrer K, Seethala RR (2014) Overexpression of lymphoid enhancer-binding factor 1 (LEF1) in solid-pseudopapillary neoplasms of the pancreas. Mod Pathol 27:1355-1363. https://doi.org/10.1038/modpathol.2014.40

32. Brachtel EF, Sanchez-Estevez C, Moreno-Bueno G, Prat J, Palacios J, Oliva E (2005) Distinct molecular alterations in complex endometrial hyperplasia $(\mathrm{CEH})$ with and without immature squamous metaplasia (squamous morules). Am J Surg Pathol. https:// doi.org/10.1097/01.pas.0000171001.87599.e2

33. Pavlakis K, Messini I, Vrekoussis T, Panoskaltsis T, Chrysanthakis D, Yiannou P, Voulgaris Z (2011) MELF invasion in endometrial cancer as a risk factor for lymph node metastasis. Histopathology 58:966-973. https://doi.org/10.1111/j.1365-2559.2011. 03802.x

34. Moreno-Bueno G, Hardisson D, Sanchez C, Sarrio D, Cassia R, Garcia-Rostan G, Prat J, Guo M, Herman JG, Matias-Guiu X, Esteller M, Palacios J (2002) Abnormalities of the APC/betacatenin pathway in endometrial cancer. Oncogene 21:7981-7990. https://doi.org/10.1038/sj.onc.1205924

35. Moreno-Bueno G, Hardisson D, Sarrio D, Sanchez C, Cassia R, Prat J, Herman JG, Esteller M, Matias-Guiu X, Palacios J (2003) Abnormalities of E- and P-cadherin and catenin (beta-, gammacatenin, and p120ctn) expression in endometrial cancer and endometrial atypical hyperplasia. J Pathol 199:471-478. https://doi. org/10.1002/path.1310 
Publisher's note Springer Nature remains neutral with regard to jurisdictional claims in published maps and institutional affiliations.

\section{Authors and Affiliations}

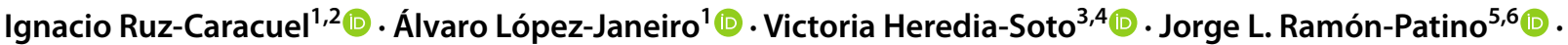 Laura Yébenes ${ }^{1,7}$. Alberto Berjón ${ }^{1,7}$ - Alicia Hernández ${ }^{8,9}$ - Alejandro Gallego $0^{4,5}$ - Patricia Ruiz ${ }^{7}$. Andrés Redondo $^{5,9}$ (1) Alberto Peláez-García ${ }^{7}\left[\right.$ Marta Mendiola ${ }^{4,7}(1) \cdot$ David Hardisson ${ }^{1,4,7,9}$}

1 Department of Pathology, Hospital Universitario La Paz, IdiPAZ, 28046 Madrid, Spain

2 Present Address: Department of Pathology, Hospital Universitario Ramón Y Cajal, IRYCIS, 28034 Madrid, Spain

3 Translational Oncology Research Laboratory, Hospital La Paz Institute for Health Research (IdiPAZ), 28046 Madrid, Spain

4 Center for Biomedical Research in the Cancer Network (Centro de Investigación Biomédica en Red de Cáncer, CIBERONC), Instituto de Salud Carlos III, 28046 Madrid, Spain

5 Department of Medical Oncology, Hospital Universitario La Paz, IdiPAZ, 28046 Madrid, Spain
6 Present Address: Department of Medical Oncology, Hospital Universitario Rey Juan Carlos, Móstoles, 28933 Madrid, Spain

7 Molecular Pathology and Therapeutic Targets Group, Hospital La Paz Institute for Health Research (IdiPAZ), Paseo de la Castellana, 261, 28046 Madrid, Spain

8 Department of Obstetrics \& Gynecology, Hospital Universitario La Paz, IdiPAZ, 28046 Madrid, Spain

9 Faculty of Medicine, Universidad Autónoma de Madrid, 28029 Madrid, Spain 